\title{
CHALLENGES TO INCREMENTAL HOUSING DEVELOPMENT IN IBADAN MUNICIPALITY
}

\author{
Gideon Oluwaseyi ADEYENI * \\ Department of Urban and Regional Planning Obafemi Awolowo University, Ile- Ife, Osun State Nigeria, \\ e-mail: adeyenioluwaseyi@gmail.com \\ Lasun Mykail OLAYIWOLA \\ Department of Urban and Regional Planning Obafemi Awolowo University, Ile- Ife, Osun State Nigeria, \\ e-mail: 1asmol2001@yahoo.com \\ Victor Abimbola ONIFADE \\ Department of Urban and Regional Planning University of Lagos, Lagos State Nigeria \\ e-mail: vonifade@unilag.edu.ng \\ Michael Babatunde Olamiju ADEGBILE \\ Department of Architecture, University of Lagos, Lagos State Nigeria, \\ e-mail: mboadegbile@yahoo.com
}

Citation: Adeyeni, G. O., Olayiwola, L. M., Onifade, V. A., Adegbile, M. B. O. (2019). Challenges to Incremental Housing Development in Ibadan Municipality. Analele Universităţii din Oradea, Seria Geografie, 29(1), 92-101. https://doi.org/10.30892/auog.291110-785

\begin{abstract}
Incremental housing despite been the major form of housing development for the low and middle income class, has suffered neglect on the path of housing policy makers in most developing countries. This has culminated in the plethora of problems facing incremental housing development in these countries today. This study examined challenges to incremental housing development in Ibadan municipality with a view to informing policy that could enhance the progressive building process. Data were obtained through questionnaire administration on incremental housing developers in the mention study area. The sampling procedure involved the stratification of the study area into high density, medium density and low density residential areas. Ten residential areas were randomly selected from the high density and medium density residential areas which are basically inhabited by low and middle income class who are the major practitioners of incremental housing development. One of every three incremental building was sampled after the random selection of the first building. A total of 305 incremental houses were sampled of the 915 identified during the pilot survey. The study revealed that lack of accessibility to finance is the most important difficulty against the incremental housing development process, while cost of building materials, land accessibility for house construction and approval of building plans were also highly rated as challenges in that order. The study concluded that non-availability of proper finance
\end{abstract}


arrangement and policy support for the low and middle income housing needs are the major challenges confronting incremental housing development in the study area.

Key words: Incremental Housing, Housing Development

$$
* \quad * \quad * \quad * \quad * \quad *
$$

\section{INTRODUCTION}

Housing is regarded as one of the basic needs. It ranks second after food and clothing. It is the pre-requisite for the survival of man (Onibokun, 1985). Housing as a unit of environment has profound influence on health, efficiency, social behaviour, satisfaction and general welfare of the community (Stone, 2006). Despite the established importance of housing, most of the urban populations in many developing countries live in dehumanizing housing environment, while those that have access to average housing do so at high cost. Most low/moderate income households therefore respond to their housing need by building as little financial resources flow in gradually. This process of gradual development/improvement of housing condition predominant among the low and middle income people is termed 'progressive housing', 'spontaneous housing' and most commonly 'incremental housing'.

Incremental housing has been describing as a 'phrased approach' for people to progressively improve their housing situation in order to achieve the constitutional right to adequate housing (Smets, 1999). For many low and middle income households, it takes a longer period of time to accumulate sufficient capital to quickly build a complete house. Most households go about the task of improving their housing condition incrementally. It is often done on a block by block and a wall by wall basis. Often the land around the home continues to accumulate building materials (stockpiling) for the next improvement project. It is an on-going process.

Challenges facing incremental housing development process in most developing countries are enormous. These problems transcend inadequate finance arrangements available for incremental housing, lack of policy support, poor level of housing infrastructure development, poor land accessibility most especially for the low and middle income households among others (Adeyeni, 2015). Aside the problem of finance, incremental housing development has suffered neglect on the path of stakeholders (including policy makers) in the housing sector (2015). Housing policy and programmes in many developing countries therefore do not recognize the abilities and motivation of the low and middle income classes of the society. The net result is the very slow pace of the incremental housing process and the resultant inadequate hosing for low/moderate income class of the society in developing countries.

As families grow and resources permit, low and middle income households build their homes step-by-step. Resources dedicated to incremental housing have to compete with other needs of the household. Not surprisingly, the incremental home building process can take low and middle income families' decades - a median of 16 years to complete a home in one study conducted in Mexico (Prahalad, 2005). Stakeholders in the housing sector have often neglected institutional arrangements concerning incremental housing development that can vastly increase the speed and performance of the progressive building process. Such institutional arrangements play an important role in incremental housing practice (Roberto, 2013). This neglect has resulted in the mirage of challenges facing incremental housing development in the developing countries of the world. This paper therefore examines the challenges to incremental housing in Ibadan municipality with a view to informing policy formulation for enhanced incremental housing development.

\section{LITERATURE REVIEW}

Various definitions of housing exist in literature. One convergence point however is that housing is basic necessity for man, a dwelling place for his kind. Housing embraces all the social services and utilities that make a community or a neighbourhood a livable environment (Agbola, 
2000). According to Olotuah (2009), housing caters for man's biological (clean air, water); psychological needs (satisfaction, contentment, prestige, privacy, choice, freedom, security and social interaction with others, human development, cultural activities) among others. Housing is more than mere shelter (Olotuah, 2009). It is one of man's most precious possessions. It offers man both physical and psychological protection. It is also a symbol of man's conquest of the earth, a monument to his power and glory. Housing can be summarized as the process and substance by which the earth has been transformed from the primordial jungle into what is today a living and ever-growing testimony of man's relentless quest to make earth amore comfortable place to live in (Olayiwola, 2012). Housing represents one of the most basic human needs. As a unit of environment, housing has a profound influence on the health, efficiency, social behaviour, satisfaction and general welfare of the community (Onibokun, 1985). It is one of the best indicators of a person's standard of living and his or her place in the society (Olayiwola, 2012).

Agbola (2000) expresses he crises situation of housing condition in Nigeria when he opined that it is conspicuously glaring that most of the urban population live in dehumanizing housing environment while those that have access to average housing do so at abnormal cost. According to Onibokun (1985) and Agbola (2000), rent in major cities of Nigeria constitute amount $60 \%$ of total expenditure an average workers disposable income. This is far higher than between 20 and $30 \%$ recommended by the United Nations. Many developers have difficulty obtaining capital for their projects even in normal times. This has been attributed to a number of problems. Two of these problems are the high interest rates that contribute to the high cost of housing, and the difficulty in obtaining capital for home construction are noteworthy (UN-Habibat, 2013). In a tight money market, housing is the first area to suffer (Roberto, 2013), since neither the builder nor the consumer can readily obtain finance for housing. It is estimated that $80 \%$ of housing in the developing world are built in this manner (Roberto, 2013) - a phenomenon that has made incremental housing a recognized housing development mechanism among housing scholars.

In the 1960s and 70s, World Bank Policies on housing promoted self-help housing. This was influenced by the writings of Turner and Fichter (1972). They indicated that self-helping housing was a solution to low-income groups housing needs. Turner agrued that self-help housing is adapted to the changing needs and circumstance of its occupants, it is improved over time when family finances allow, it enables community solidarity and mutual help and above all, the owners have the autonomy to design and manage their dwellings. Turner further added that individual needs, priorities and possibilities are continually changing and that helps to even spread the cost of construction over time. The component materials needed for construction should therefore be left with individuals and households or decentralized local and small scale institutions. According to Turner's view, large organizations provide standard products which cannot deal with the enormous changing housing needs of the low-income households (Turner and Fichter, 1972). The role of government according to them was to ensure access to land, building materials and finance. These ideas were later incorporated in the World Bank lending programmes (Smets, 1999). There writings remain a major reference in promoting incremental housing development today.

According to Smets (1999), incremental building is the process by which shelter is constructed step by step and improved over a period of time in terms of quality and size. Smets argues that, this type of building process depends much on the individual household priorities and available income, and changes in accordance to the family cycle. CHF (2004) defines incremental building as a household-driven building process for acquiring, extending, improving or servicing a dwelling or group of dwellings over time, and thereby improving the quality of the household members and maximizing their choices of housing design and housing needs. The incremental/progressive building or development is also seen as the process by which low-income households make incremental investments in housing as their income permit (Hasan, 2000). What is apparent in these three definitions of incremental building is the issue of limited capacity or incomes and hence the only possibility of house ownership for the low-income household is to invest in shelter in several stages (UNCHS, 2003). Studies have reported that incremental housing 
developers take to various dwelling forms depending on the opportunities and challenges surrounding the progressive dwelling process (Adeyeni, 2015).

On the basis of structure, design or layout, houses can be categorized into the following:

I. Single detached bungalow - These are houses which are completed independent of any other structure. The garage may be located within the house or in a separate structure. Detach houses are generally owner-occupied and of one floor (Jinadu, 2007). Typical examples of detached housing are the three bedroom houses found in Gwarinpa housing estate in Abuja, Nigeria.

II. Semi-detached bungalow - These are one or two family houses, with a common wall between houses for economy. They are characterized by separate and independent entrances. Semi-detached bungalows are similar to the detached ones but are located on a smaller lot. Semidetached bungalows are usually in one floor. Construction in semi-detached are cheaper than in single detached house but it has less privacy

III. Row house - these are roomy apartments found in many cities and rural settlements in Nigeria. Common walls are used for both sides of row houses for economy. They are narrow in shape to maximize number of units in a row and are cheaper to build (Olayiwola, 2012). A typical row housing contains multiple-room facility that offers single rooms (between 6 to 10 rooms aside, separated by a narrow lobby) for rent with shared kitchen, bathroom and toilet facilities.

IV. House with more than one floor - these are houses more than a single floor. They may also be referred to as low rise buildings. They may be detached, semi-detached or rooming apartments. The common ones are the two and three storey buildings (Olayiwola, 2012).

The challenges to incremental housing as recorded in literature are enormous. Minimum housing standards and legislation are usually outside the social contexts of the low-income class (Walker, 2001). A major obstacle for housing experts is how to situate housing standards in different social contexts. Also, the real estate market rarely produces sub-divided and serviced land for low-income families (Jacobs and Savedoff, 1999). Consequently, they must access land through alternate means, such as illegal land occupation, purchases of illegal subdivisions and government programs and they must also be prepared to accept different level of security in land adequate tenure. Walker (2001) noted that a major challenge against the progressive building process is the lack of adequate resources on the part of housing developers. Aravena (2011), Farvacque and McAuslan (1992), Greene and Duran (1990) posits that while the public sector favours access to sanitation services as the most crucial need, households mostly value maximum protection against the elements (relative to their previous situation of squatting on illegal land that might be overly susceptible to natural risks) and some privacy (relative to their previously overcrowded circumstances). This may question the integrity of incremental housing development as a possible viable low income housing development option.

\section{THE STUDY AREA}

Ibadan is the capital city of Oyo state in Nigeria; the city is located in the southwestern part of the county. It is located approximately between longitudes $3^{\circ} 53^{\prime}$ and $4^{\circ} 10^{\prime}$ east of the Greenwich Meridian and latitudes $7^{\circ} 22^{\prime}$ and $7^{\circ} 40^{\prime}$ north of the Equator (figure 1). The military Jihad war of the $19^{\text {th }}$ century originating from Sokoto Caliphate which caused the collapse of the old Oyo Empire provoked a huge movement of people from the north to the south of Yoruba land. Ibadan subsequently became a war camp by 1829 for warriors coming from Oyo, Ife and Ijebu (Mabogunje, 1962). Moreover, its location at the fringe of the forest promoted its emergence as a marketing centre for traders and goods from both the forest and grassland areas. The city is located on an elevation of 234 meters above sea level and it is situated on gently rolling hills running in a northwest/southwest direction (Agbola, 2000). The city succeeded in becoming a large empire from around 1860 s to 1890 s. Ibadan witnessed a rapid growth when it became the Western Province Headquarters in 1939. The built up area of Ibadan was said to be $38.85 \mathrm{sq} / \mathrm{km}$ in 1935 ; $46.40 \mathrm{sq} / \mathrm{km}$ in $1955 ; 77.7 \mathrm{sq} / \mathrm{km}$ in $1965 ; 152.80 \mathrm{sq} / \mathrm{km}$ in 1988 . By the year 2000 , it is estimated that Ibadan covered $400 \mathrm{sq} / \mathrm{km}$. 
According to Agbola (2000), the five local government areas that make up Ibadan municipality encompasses Ibadan North, Ibadan North East, Ibadan North West Ibadan South East and Ibadan South West with respective headquarters at Agodi-Gate, Iwo Road, Onireke, Mapo and Oluyole. The peculiarity of the five areas is that they are connected with main roads that government areas which are rural include Akinyele, Egbeda, Ido, Lagelu, Oluyola and Ona-Ara. Spatially, Ibadan sprawls over a radius of $12-15 \mathrm{~km}$. At a crow fly, Ibadan is $128 \mathrm{~km}$ northeast of Lagos and $345 \mathrm{~km}$ southwest of Abuja. It enjoys the distinctive West African Monsoon climate which has two major seasons: the dry and wet, the occurrence of which is greatly influenced by its latitudinal location. Since the time of the 1986 Structural Adjustment Programme (SAP), thousands of small-scale and household industries have been established in Ibadan. Consequently, there was an increase in employment in the informal economic sector in the 1980s, the development of corruption and bad government administration increased dramatically during the military era notably during Babangida and Abacha regimes (1984-1998) (Mabogunje, 1962).

Housing and associated facilities (water, electricity, etc) have been reported to be inadequate in Ibadan, such that hundreds of households live in substandard and subhuman environments, plagued by slums, squalor, and similarly inadequate social amenities, such as schools and health and recreational facilities (Agbola, 2000). The gradual decline of social values and the breakdown of family cohesiveness and community spirit have resulted in increased levels of juvenile delinquency and crime. The level of provision of infrastructural facilities has declined, and intracity mobility is greatly hindered by poorly planned and inefficiently managed land use and a sharply reduced network of roads. The housing situation of Ibadan therefore presents a good case for studies with implication for informing policy formulation in the developing countries of the world.

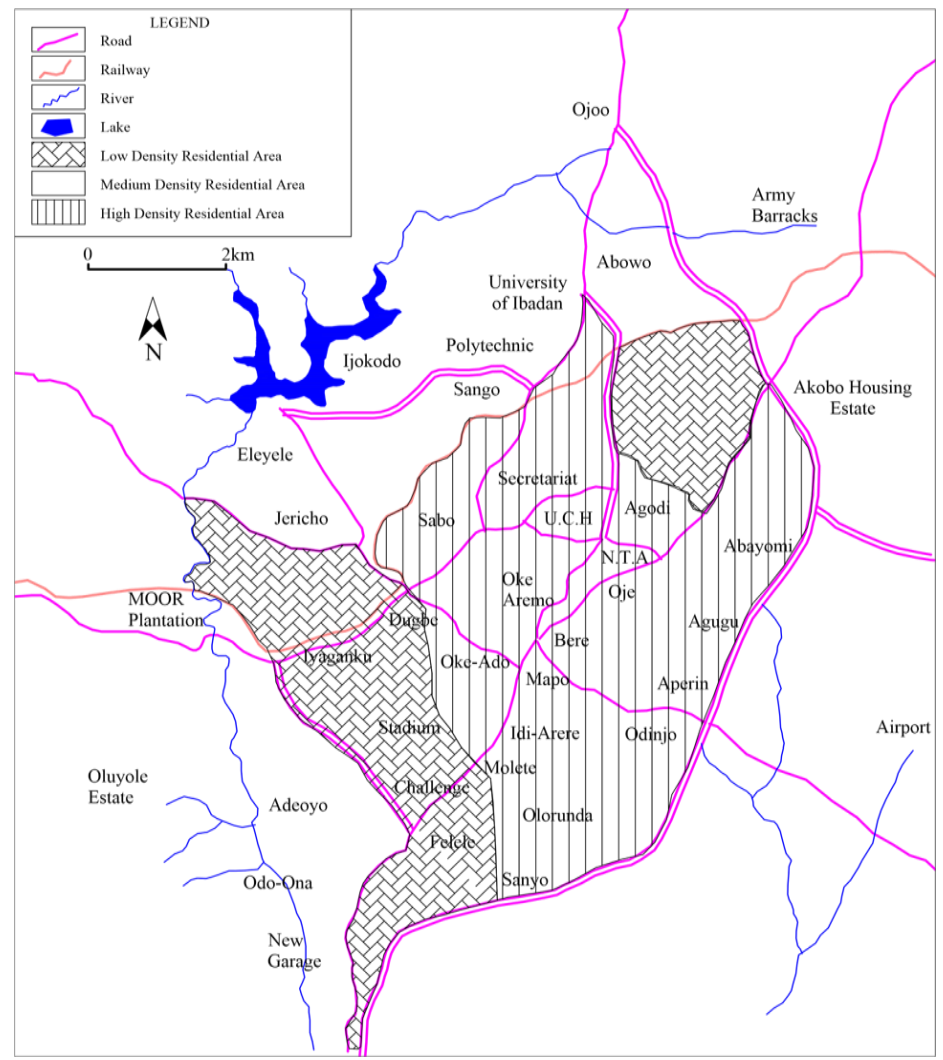

Figure 1. Map of Ibadan showing the major residential wards Sources: Ibadan North Local Government Area Local Planning Authority Scale 


\section{RESEARCH METHODOLOGY}

Data were collected from primary source for the purpose of achieving the aim of this study.

Primary data were collected through administration of questionnaire. The questionnaires were directed at the developers of incremental houses in the study area. Sample frame for this study are developers of incrementally built houses in the selected five local government areas of Ibadan municipality. Incremental houses here considered are occupied houses under construction or improvement, whose part or whole outer wall has not been plastered; and/or whose flooring has not been completed; and /or whose outer windows or doors are made of temporary materials. Multi-stage sampling technique was employed in the study. Firstly, stratification of the study area into the existing local government area delineation was carried out. In the second stage, the five local government areas were divided into the existing residential wards as defined by the National Population Commission in the conduct of census.

The residential wards were thereafter stratified into the three identifiable residential densities - low, medium and high - as employed by Adesanya (2000). Table 3.2 shows that thirty three (33) low density, sixty eight (68) medium density and sixty three (63) high density residential wards can be identifies in the five local government areas. From these, $8 \%$ of the wards in the medium and high density areas wee randomly selected to make a total of 10 wards in the two residential density areas. Aside the consideration of time and cost, the selection of one ward from each of the high and medium density residential areas was based on the belief that residential areas of the same density in each of the local government areas are nearly uniform in their housing characteristics and so information obtained from one could provide a good insight into what is obtainable in the other wards of the same density. The low density residential wards were not considered as they are mainly occupied by the high income earners who may not engage in incremental housing as such.

For the ten (10) selected residential wards, developers of incremental houses were selected using the simple process of sympathetic sampling from the nine hundred and fifteen (915) incremental houses identifies during the pilot survey. A total of 305 houses representing $33 \%$ of the sample frame were sampled. In the case, the first house sampled was selected randomly. The subsequent selection was on the basis of every 3rd incremental house. This is presented in Table 3.3. Developers of incremental housing were administered a questionnaire and direct observation carried out. The data collected were analysed using frequency distribution, percentages, ANOVA and multiple regressions.

To this end, seven major difficulties were identifiable in the study area as revealed by the self administered questionnaire. Each of the difficulties were rated using one of the five likert scales as follows: Highly Applicable (HA), Applicable (A), Just Applicable (JA), Not Applicable (NA) and Not Applicable At All (NAA). This is a personally devised rating to measure perceived difficulties against the progressive development process. For ease of measurement and understanding, the difficulties were measured using an index called Perceived Index (PI).

Identifies possible difficulties rated by the developers include: cost of building materials, land accessibility for house construction, tenure security for land before house construction, approval of plans/property documentations, accessibility to finance, housing appearance at the earlier stage of incremental construction, attitude of household members to moving into the incremental dwelling.

To arrive at an index for each difficulty, the following steps were followed:

a) A Weight Value of 5,4,3,2 and 1 were attached to each of the rating respectively;

b) Summation of Weight Value (SWV) which is the addition of the product of value attached to a rating and respective number of respondents to the rating;

c) Dividing the SWV by the number of the rated factor.

Using the above rating, the mean index for all difficulties in each residential zone and the study area were computed by summing up the index to each of the difficulties and dividing by the number of difficulties identifies (n): $n=7$. 


\section{ANALYSIS AND DISCUSSION}

Presented in Table 1, 2 and 3 are developers' perception of how significant the identified difficulties are in the two concerned residential density areas and the study area as a whole. From this summary, difficulties against the incremental development process can be grouped into two, relative to how significant the impact is perceived. These were grouped with positive deviation and group with negative deviation from the mean index. It was evident from the tables that four difficulties against the incremental development process had a positive deviation from the mean index in the high and medium density residential areas and the study area as a whole. Three of the identified difficulties had negative deviation around the means and were so considered to have exalted title hindrance on the incremental development process.

As presented in table 1, incremental housing developers in the study area as a whole were of the opinion that accessibility to finance, cost of building materials, tenure security and land accessibility for house construction are the most important difficulties against the incremental housing developers in Ibadan municipality. Approval of building plans were rated to exalt the next most significant difficulty on the incremental development process above the two last factors which are more of socio-psychological hindrances to the incremental housing development process. The last two difficulties - attitude of household members to moving into dwelling and dwelling appearance at the earlier stage of the incremental development process - were not much rated by the developers. This corroborates the findings of Llanto (2007), who using a case of the Philippines affirmed that low and middle income household exhibits a high level of motivation to own a hose of their own and will go far in satisfying their house desire.

As recorded on table 1, accessibility to finance, cost of building materials, tenure security for land before construction, land accessibility for house construction, approval of plans/property documentations, attitude of household members to moving into the incremental dwelling and housing appearance at the earlier stage of incremental construction had indices of 4.91, 4.19, 3.66, 3.55, 3.33, 2.43 and 2.21 respectively. The computed standard deviation and co-efficient of the variation were 0.9419 and $27.09 \%$. It could therefore be inferred that the scattering of developers' response around the mean PI was low and the result of the analysis is so considerable for making inference.

Table 1. Developers perception of how significant identifies difficulties are in the study area

Data source: Author's field survey (2015)

\begin{tabular}{|l|l|l|l|l|l|l|l|l|}
\hline Difficulties & HA & A & JA & NA & NAA & SWV & PI & MD \\
\hline Accessibility to finance & 277 & 28 & 0 & 0 & 0 & 1497 & 4.91 & 1.44 \\
\hline Cost of building materials & 110 & 144 & 51 & 0 & 0 & 1279 & 4.19 & 0.72 \\
\hline Tenure security for land before construction & 101 & 74 & 63 & 52 & 10 & 1116 & 3.66 & 0.19 \\
\hline Land accessibility for house construction & 83 & 115 & 66 & 33 & 8 & 1082 & 3.55 & 0.08 \\
\hline Approval of plans/property documentations & 79 & 77 & 49 & 65 & 35 & 1015 & 3.33 & -0.14 \\
\hline $\begin{array}{l}\text { Attitude of household members to moving into } \\
\text { the incremental dwelling }\end{array}$ & 32 & 41 & 47 & 90 & 96 & 741 & 2.43 & -1.04 \\
\hline $\begin{array}{l}\text { Housing appearance at the earlier stage of } \\
\text { incremental construction }\end{array}$ & 20 & 29 & 43 & 105 & 118 & 673 & 2.21 & -1.26 \\
\hline
\end{tabular}

Note: highly applicable (HA), Applicable (A), Just Applicable (JA), Not Applicable (NA) and Not Applicable at all (NAA)

$$
\sum \mathrm{PI}=24.28, \overline{\mathrm{PI}}=\frac{\sum \mathrm{PI}}{\mathrm{N}=7}=\frac{28.28}{7}=3.47
$$

Standard Deviation $(\mathrm{SD}) \sqrt{ }$ Variance $=\sqrt{ } 0.887=0.9419$

$$
\text { Co-efficient of Variation }=\left[\left(\frac{S D}{P I}\right) \times 100\right] \%=\left[\left(\frac{0.94}{3.47}\right) \times 100\right] \%=27.09 \%
$$

Table 2 shows that incremental housing developers in the high density residential areas also rate accessibility to finance as the most significant difficulty against the progressive building process with an index of 4.92. In the order of importance as rated by the developers, other 
identified difficulties are cost of building materials, tenure security for land before construction, land accessibility for house construction, approval of plans/property documentations, attitude of household members to moving into the incremental dwelling and housing appearance having an index of $4.31,3.70,3.61,3.28,2.42$ and 2.12 respectively. The computed standard deviation and co-efficient of variation were 0.9866 and $28.45 \%$ respectively. It will therefore not be wrong to infer that the scattering of developers' responses around the mean PI makes the result of the analysis reliable for making inference.

Table 2. Developers perception of how significant identifies difficulties are in the high density residential areas Data source: Author's field survey (2015)

\begin{tabular}{|l|l|l|l|l|l|l|l|l|}
\hline Difficulties & HA & A & JA & NA & NAA & SWV & PI & MD \\
\hline Accessibility to finance & 156 & 14 & 0 & 0 & 0 & 836 & 4.92 & 1.44 \\
\hline Cost of building materials & 67 & 88 & 15 & 0 & 0 & 732 & 4.31 & 0.83 \\
\hline Tenure security for land before construction & 62 & 39 & 31 & 32 & 6 & 629 & 3.70 & 0.22 \\
\hline Land accessibility for house construction & 41 & 57 & 44 & 21 & 7 & 614 & 3.61 & 0.13 \\
\hline Approval of plans/property documentations & 38 & 46 & 32 & 33 & 21 & 557 & 3.28 & -0.20 \\
\hline $\begin{array}{l}\text { Attitude of household members to moving into } \\
\text { the incremental dwelling }\end{array}$ & 17 & 24 & 26 & 49 & 54 & 4111 & 2.42 & -1.06 \\
\hline $\begin{array}{l}\text { Housing appearance at the earlier stage of } \\
\text { incremental construction }\end{array}$ & 11 & 16 & 21 & 56 & 66 & 360 & 2.12 & -1.36 \\
\hline
\end{tabular}

Note: highly applicable (HA), Applicable (A), Just Applicable (JA), Not Applicable (NA) and Not Applicable at all (NAA)

$\sum \mathrm{PI}=24.36, \overline{\mathrm{PI}}=\frac{\sum \mathrm{PI}}{\mathrm{N}=7}=\frac{28.36}{7}=3.48$

Standard Deviation $(\mathrm{SD}) \sqrt{\text { Variance }}=\sqrt{0.973}=0.9866$

Co-efficient of Variation $=\left[\left(\frac{S D}{P I}\right) \times 100\right] \%=\left[\left(\frac{0.99}{3.48}\right) \times 100\right] \%=28.45 \%$

As shown in table 3 , incremental housing developers in the high density residential areas also rate accessibility to finance as the most significant difficulty against the progressive building process with an index of 4.90. In the order of importance as rated by the developers, other identified difficulties are cost of building materials, tenure security for land before construction, land accessibility for house construction, approval of plans/property documentations, attitude of household members to moving into the incremental dwelling and housing appearance having an index of 4.05, 3.61, 3.47, 3.39, 244 and 2.32 respectively. The computed standard deviation and co-efficient of variation were 0.8934 and $25.80 \%$ respectively. It will therefore not be wrong to infer that the scattering of developers' responses around the mean PI makes the result of the analysis reliable for making inference.

Table 3. Developers perception of how significant identifies difficulties are in the medium density residential areas Data source: Author's field survey (2015)

\begin{tabular}{|l|l|l|l|l|l|l|l|l|}
\hline Difficulties & HA & A & JA & NA & NAA & SWV & PI & MD \\
\hline Accessibility to finance & 121 & 14 & 0 & 0 & 0 & 661 & 4.90 & 1.45 \\
\hline Cost of building materials & 43 & 56 & 36 & 0 & 0 & 547 & 4.05 & 0.60 \\
\hline Tenure security for land before construction & 43 & 35 & 32 & 16 & 4 & 487 & 3.61 & 0.16 \\
\hline Land accessibility for house construction & 35 & 40 & 25 & 23 & 12 & 468 & 3.47 & 0.02 \\
\hline Approval of plans/property documentations & 41 & 31 & 17 & 32 & 14 & 458 & 3.39 & -0.06 \\
\hline $\begin{array}{l}\text { Attitude of household members to moving into } \\
\text { the incremental dwelling }\end{array}$ & 15 & 17 & 21 & 41 & 42 & 330 & 2.44 & -1.01 \\
\hline $\begin{array}{l}\text { Housing appearance at the earlier stage of } \\
\text { incremental construction }\end{array}$ & 9 & 13 & 22 & 49 & 52 & 313 & 2.32 & -1.13 \\
\hline
\end{tabular}

Note: highly applicable (HA), Applicable (A), Just Applicable (JA), Not Applicable (NA) and Not Applicable at all (NAA) 
$\sum \mathrm{PI}=24.18, \overline{\mathrm{PI}}=\frac{\sum \mathrm{PI}}{\mathrm{N}=7}=\frac{24.18}{7}=3.45$

Standard Deviation $(\mathrm{SD}) \sqrt{\text { Variance }}=\sqrt{0.798}=0.8934$

Co-efficient of Variation $=\left[\left(\frac{S D}{P I}\right) \times 100\right] \%=\left[\left(\frac{0.89}{3.45}\right) \times 100\right] \%=25.80 \%$

From the analysis above it is obvious that a slight difference exist in the perception of difficulties the incremental development process between the high and medium density residential areas. For instance, the index of accessibility to finance in the high density residential areas is 4.92; the same index had a value of 4.90 in the medium density residential areas. It is equally noticeable that approval of building plans has a higher index than attitu de of household members to moving into the incremental dwelling and housing appearance at earlier stage of incremental construction. This creates concern about the perception of the importance of physical planning by the developers.

\section{CONCLUSION AND RECOMMENDATIONS}

The study revealed that developers perceived lack of accessibility to finance as the most important difficulty against incremental housing development process, while cost of building materials, land accessibility for house construction and approval of building plans were also highly rated as challenges. It is however noteworthy that the motivation of the low and middle income households to have a roof of their own over their head has led to the development of various structures which households improve as resources permits. Thus, it can be concluded that non-availability of proper finance arrangements and policy support for the low and middle income housing needs are the major challenges confronting incremental housing development in the study area.

It is beyond doubt that most incremental housing developers would benefit enormously form technical and legal assistance provided by governmental bodies, NGOs or the private sector. The workability of microfinance for incremental housing developments can be investigated and its prospects harnessed as it has been proven to adapt to evolving needs of the low and middle income groups in developing countries of Asia and the Caribbean. Incremental housing, including its mutual form, should be better monitored and in due course, better 'assisted' by government and housing institutions, thus securing that it will become a basic part of formal housing policies. Government should develop an effective and efficient support system by involving in its through production of necessary housing facilities along with the environmental and infrastructural facilities. The advent of the Land Use Act and the instrument of Certificate of Occupancy have fuelled unprecedented speculation, private ownership and commercialization of land. The unbridled corruption and high-handedness encourage by the Act have also defeated the equity and accessibility advantages that the Act had intended to ensure. These recommendations could create a pathway towards enhanced incremental housing development in the developing world.

\section{REFERENCES}

Adesanya, A. (2000). Partnerships in the Planning and Management of Cities: A Case Study of the Sustainable Ibadan Project (SIP) (No. 8). Nigerian Institute of Social and Economic Research.

Adeyeni, G. O. (2015). A study of incremental housing development in Ibadan municipality, Nigeria (Doctoral dissertation, MSc. Dissertation submitted to the department of Urban and Regional Planning, Obafemi Awolowo University Ile-Ife, Nigeria).

Agbola T. (2000). Housing, Poverty and Environment - The Nigerian situation. A seminar Paper presented at a workshop on Effective approach to Housing delivery in Nigeria. Organised by the Nigerian Institute of Building, Ibadan, Nigeria.

Aravena, A. (2011). Elemental: A Do Tank. In Latin America at the Crossroads: Architectural design, edited by Mariana Leguia. London, United Kingdom: John Wily \& Sons: $32-37$.

CHF (2004). Strategic Assessment of the Affordable Housing Sector in Ghana. CHF International, Silver Spring, MD.

Farvacque, C., \& McAuslan, P. (1992). Reforming urban land policies and institutions in developing countries. The World Bank. 
Greene, M., Duran, L. (1990). The Contructive Process in lots with Services, Corporation of University Promotion, Santiago, Chile.

Hasan, A. (2000). Housing for the poor: Failure of formal sector strategies. City Press.

Jacobs, M., \& Savedoff, W. D. (1999). There's More Than One Way to Get a House: Housing Strategies in Panama.

Jinad, A.M. (2007). Understanding the Basics of Housing: (A Book of study notes for students in Tertiary Institution), Jos University Press.

Llanto, G. M. (2007). Shelter finance strategies for the poor: Philippines. Environment and urbanization, 19(2), 409-423.

Mabogunje, A. (1962). The growth of residential districts in Ibadan. Geographical Review, 52(1), 56-77.

Olayiwola, L.M. (2012). The Journey through the Corridor of Housing, Inaugural Lecture Series 252, Obafemi Awolowo University, Ile-Ife.

Olotuah, O.A. (2009). Demystifying the Nigerian Urban Housing Question. Inaugural Lecture Series 53, Federal Universty of Technology, Akure, Nigeria.

Onibokun A.G. (1985). Housing Finance in Nigeria in Poju Onibokun (ed) Engineering, Nigerian Institute of Social and Economic Research (NISER), Ibadan

Prahalad, C.K. (2005). The fortune at the bottom of the pyramid, Upper Saddle River, New Jersey: Wharton School Publishing. Roberto, C. (2013). Incremental housing: The Past and Future Dwelling Solution for the Poor, MIT Press, Massachusett.

Smets, P. (1999). Housing finance trapped in a dilemma of perceptions: Affordability criteria for the urban poor in India questioned. Housing Studies, 14(6), 821-838.

Stone, M. E. (2006). A housing affordability standard for the UK. Housing Studies, 21(4), 453-476.

Turner, J. F., \& Fichter, R. (Eds.). (1972). Freedom to build: dweller control of the housing process. Macmillan.

UNCHS (2003). The Challenge of Slum: Global Report on Human settlement 2003, First Published in the UKand USA in 2003 by Earthscan Publications Ltd., Nairobi, Kenya.

UN-Habibat (2013). Global Housing Strategy: Framework Document.

Walker, A. (2001). The social context of build form: the case of informal housing production in Mexico City. Working paper No 114, development and planning unit, University College, London.

Submitted:

June 22, 2018
Revised:

March 13, 2019
Accepted and published online May 21, 2019 